\title{
An evaluation of respiratory administration of measles vaccine for prevention of acute lower respiratory infections in children
}

Daisy Higginson ${ }^{1 \dagger}$, Evropi Theodoratou ${ }^{1 \dagger}$, Harish Nair ${ }^{1,2 \dagger}$, Tanvir Huda ${ }^{3}$, Lina Zgaga' ${ }^{1}$ Suresh S Jadhav ${ }^{4}$, Saad B Omer ${ }^{5}$, Igor Rudan ${ }^{1,6+}$, Harry Campbell ${ }^{1 *+}$

\begin{abstract}
Background: Measles was responsible for an estimated 100,000 deaths worldwide in 2008. Despite being a vaccine-preventable disease, measles remains a major cause of morbidity and mortality in young children. Although a safe and effective injectable measles vaccine has been available for over 50 years it has not been possible to achieve the uniformly high levels of coverage (required to achieve measles eradication) in most parts of the developing world. Aerosolised measles vaccines are now under development with the hope of challenging the delivery factors currently limiting the coverage of the existing vaccine.
\end{abstract}

Methods: We used a modified CHNRI methodology for setting priorities in health research investments to assess the strengths and weaknesses of this emerging intervention to decrease the burden of childhood pneumonia. This was done in two stages. In Stage I, we systematically reviewed the literature related to emerging aerosol vaccines against measles relevant to several criteria of interest. Although there are a number of different aerosol vaccine approaches under development, for the purpose of this exercise, all were considered as one intervention. The criteria of interest were: answerability; cost of development, production and implementation; efficacy and effectiveness; deliverability, affordability and sustainability; maximum potential impact on disease burden reduction; acceptability to the end users and health workers; and effect on equity. In Stage II, we conducted an expert opinion exercise by inviting 20 experts (leading basic scientists, international public health researchers, international policy makers and representatives of pharmaceutical companies). The policy makers and industry representatives accepted our invitation on the condition of anonymity, due to the sensitive nature of their involvement in such exercises. They answered questions from the CHNRI framework and their "collective optimism" towards each criterion was documented on a scale from 0 to $100 \%$.

Results: The panel of experts expressed mixed feelings about an aerosol measles vaccine. The group expressed low levels of optimism regarding the criteria of likelihood of efficacy and low cost of development (scores around 50\%); moderate levels of optimism regarding answerability, low cost of production, low cost of implementation and affordability (score around 60\%); and high levels of optimism regarding deliverability, impact on equity and acceptability to health workers and end-users (scores over 80\%). Finally, the experts felt that this intervention will have a modest but nevertheless important impact on reduction of burden of disease due to childhood pneumonia (median: 5\%, interquartile range 1-15\%, minimum 0\%, maximum 45\%).

Conclusion: Aerosol measles vaccine is at an advanced stage of development, with evidence of good immunogenicity. This new intervention will be presented as a feasible candidate strategy in the campaign for global elimination of measles. It also presents an unique opportunity to decrease the overall burden of disease due to severe pneumonia in young children.

* Correspondence: Harry.Campbell@ed.ac.uk

† Contributed equally

${ }^{1}$ Centre for Population Health Sciences, Global Health Academy, The

University of Edinburgh, UK

Full list of author information is available at the end of the article 


\section{Background}

Despite the availability of an effective vaccine, the global burden of disease due to measles continues to be high in young children. Although the coverage of the first dose of measles vaccine improved dramatically in the twenty first century, it is estimated that in the year 2008 approximately 100,000 deaths in children aged less than 5 years was attributable to measles $[1,2]$. Failure to achieve universal coverage for at least one dose of measles vaccine remains the key reason for these deaths. Pneumonia is one of the most common fatal complications of measles [3]. In 2008, all World Health Organization (WHO) member states reaffirmed their commitment to reduce the global measles mortality to less than 75,000 deaths by 2010 (i.e. $90 \%$ reduction in measles mortality compared to the year 2000) [4]. This would in turn contribute to an overall reduction in burden of disease due to childhood pneumonia.

The debate regarding the feasibility of achieving a measles free world has been ongoing for the last two decades. The meeting of the International Task Force for Disease Eradication in June 2009 evaluated the available evidence for the potential eradicability of measles and concluded with greater confidence (than at the previous meeting in 2002) that "measles eradication is biologically possible using available tools... Research to discover new tools or to improve existing ones is needed to strengthen the arsenal against this contagious disease. Any practical breakthrough in ways to mitigate any of the current requirements to inject, provide 2 doses, refrigerate measles vaccine, and to improve efficacy in young infants, would be a major contribution to measles eradication" [5]. Two of the major components of the comprehensive strategy for measles eradication were achieving and maintaining high coverage $(>90 \%)$ with the routinely scheduled first dose of measles-containing vaccine (MCV1) among children aged 1 year and to ensure that all children receive a second opportunity for measles immunization (either through a second routine dose or through periodic supplementary immunization activities (SIAs)). However, to implement these strategies in the field, a more simplified and effective delivery method would need to be developed.

The injectable measles vaccine received its licensure in 1963 and since then worldwide vaccination programmes have been employed in an attempt to control the disease [6]. The existing vaccine has proved extremely efficacious in the prevention of the disease. Between 2000 and 2007 global measles mortality declined by 74 percent with a 10 percent overall increase in vaccine coverage (estimated worldwide coverage of the first dose of measles vaccine in 2007 was approximately 82 percent) [1]. However, this coverage is not uniform- there are wide disparities in coverage among countries and pockets of poor coverage remain within countries with overall coverage above 80 percent. In 2007, MCV1 coverage in WHO Africa and South East Asia regions was $74 \%$ and $73 \%$ respectively [7] - two regions particularly vulnerable to disease outbreaks and which contribute to a substantial proportion of the global disease burden of measles. WHO has identified 47 priority countries which account for the highest percentage of measles deaths and have been made the focus of a comprehensive strategy for a targeted disease reduction [4]. As a result, researchers are exploring more effective ways to achieve universal coverage of measles vaccine amongst the poorer sections of the society in low and middle income countries. One of the strategies under consideration to improve delivery of the existing measles vaccine is needle free administration of the vaccine. Such a delivery mechanism could help achieve universal coverage of the vaccine in the hard to reach areas in resource poor settings [8].

In 1983, Albert Sabin described his vision of creating an aerosolized measles vaccine [9]. His concept was to create a vaccine that was simple, safe, cost-efficient and could be easily implemented into mass vaccination campaigns. The initial vaccine developed by him was piloted in Mexico and data from the limited serological and field studies demonstrated the safety and immunogenicity of the vaccine in infants and children [10]. Following this, more than 4 million children throughout Mexico were vaccinated against measles using the aerosol route of administration during mass campaigns [11]. However, the success was limited as the aerosol vaccine (effective in children aged 1 year and above) was never tested or incoporated into routine immunization programmes. In 2002 the Measles Aerosol Project (MAP) was established to develop at least one method for respiratory delivery of currently licensed measles vaccines [12]. In addition to MAP, there are a number of other research efforts to develop and evaluate an aerosol measles vaccine.

We aimed to review the existing literature, outlining the progress of the emerging aerosol measles vaccines at all stages of development; present the evidence regarding key issues surrounding aerosolized measles vaccine and assess the level of collective optimism of international experts over its priority status for receiving investment support as a strategy to decrease pneumonia burden in children. The paper is presented as part of a series of papers, each in turn focusing on different emerging vaccines and other interventions against pneumonia.

\section{Methods}

We used a modified Child Health and Nutrition Research Initiative (CHNRI) methodology for setting 
priorities in health research investments. The methodology has been described in great detail [13-17] and implemented in a variety of settings [18-23]. Briefly, the method uses a set of pre-defined criteria and collects expert opinion of all stakeholders on the risks and benefits associated with investing in existing and / or new interventions.

\section{CHNRI exercise - stage I: Identification and selection of studies}

We applied the CHNRI method to estimate the potential impact of the aerosolized measles vaccines. We conducted a systematic literature review using the following criteria: answerability, cost of development, cost of product, cost of implementation, efficacy and effectiveness, deliverability, affordability, sustainability, maximum potential impact on disease burden reduction, acceptability to health workers, acceptability to end users and equity [13] (Figure 1). Details about the search strategies are presented in Supplementary table 1 in Additional file 1. The search was limited to Ovid MEDLINE, Embase, Global Health, Web of Science, LILACS, IndMed, and grey literature (SIGLE) databases from January 1994 to May 2009. (Although we updated the search in January 2011, for Stage II of this exercise, the experts were presented only with a summary of the literature from 1994 to May 2009). No language or publication restrictions were applied. In order to ensure completeness, we also conducted hand searching of online journals, scanned the reference list of identified citations, and perused literature available on the websites of pharmaceutical companies and international agencies (GAVI and WHO).

We used a pre-determined eligibility criteria for screening and including identified studies. In particular, we included studies on aerosolized measles vaccine derived from either Edmonston-Zagreb or Schwarz vaccine virus strains in children aged less than 15 years;studies assessing other novel interventions against measles; and studies addressing questions on answerability, effectiveness, deliverability, disease burden reduction or equity. We excluded studies reporting existing measles interventions; use of measles vaccine in the adult population; and not directly challenging the impact of vaccines.

\section{CHNRI exercise - stage II}

We shared the initial review of the literature with 20 experts. The list of chosen experts included five leading basic scientists, five international public health researchers, five international policy makers and five representatives of the pharmaceutical companies. The 20 experts were chosen based on their excellent track record in child health research (but were not specifically involved with measles disease research). We initially offered participation to the 20 experts with the greatest impact of publications in their area of expertise over the past 5 years (for basic researchers and international public health researchers), or for being affiliated to the largest pharmaceutical company in terms of vaccination programme or international agency in terms of their annual budget. For those who declined to participate (about $20 \%$ ) replacements were found using the same criteria. The policy makers and industry representatives accepted our invitation on the condition of anonymity, due to sensitive nature of their involvement in such exercises. About half of the experts were either affiliated to institutions in developing countries or had previous experience of working in developing country settings. The experts met during September 7-13, 2009 in Dubrovnik, Croatia, to conduct the $2^{\text {nd }}$ stage of CHNRI expert opinion exercise. The process of second-stage CHNRI is shown in Figure 2. All invited experts discussed the evidence provided in CHNRI stage I, and then answered questions from CHNRI framework (see Supplementary table 2 in Additional file 1). Their answers could have been "Yes" (1 point), "No" (0 points), "Neither Yes nor No" (0.5 points) or "Don't know" (blank). Their "collective optimism" towards each criterion was documented on a scale from 0 to $100 \%$. The interpretation of this metric for each criterion is simple: it is calculated as the number of points that each evaluated type of emerging aerosolized measles vaccine received from 20 experts (based on their responses to questions from CHNRI framework), divided by the maximum possible number of points (if all answers from all experts are "Yes") [13-17].

\section{Results}

We identified 51 articles and product monographs for inclusion in the study. Currently several products are in development phase, some of which have completed phase I and II clinical trials.

\section{Answerabilty}

We evaluated the likelihood of an effective aerosolised measles vaccine being available for incorporation into the routine Expanded Programme of Immunization (EPI) schedule or supplementary immunization campaigns within in a time frame of 10 years. The potential for measles aerosol vaccination has been recognized since the 1960's when American and Japanese researchers acknowledged a consistent immunogenic response in children exposed to small amounts of aerosolized, partly attenuated measles vaccine [9]. Measles is an airborne disease, with transmission of the measles virus across the respiratory mucosa. Delivery of measles vaccination using aerosol technology aims to imitate this natural pattern of infection [24]. It is assumed that aerosol 


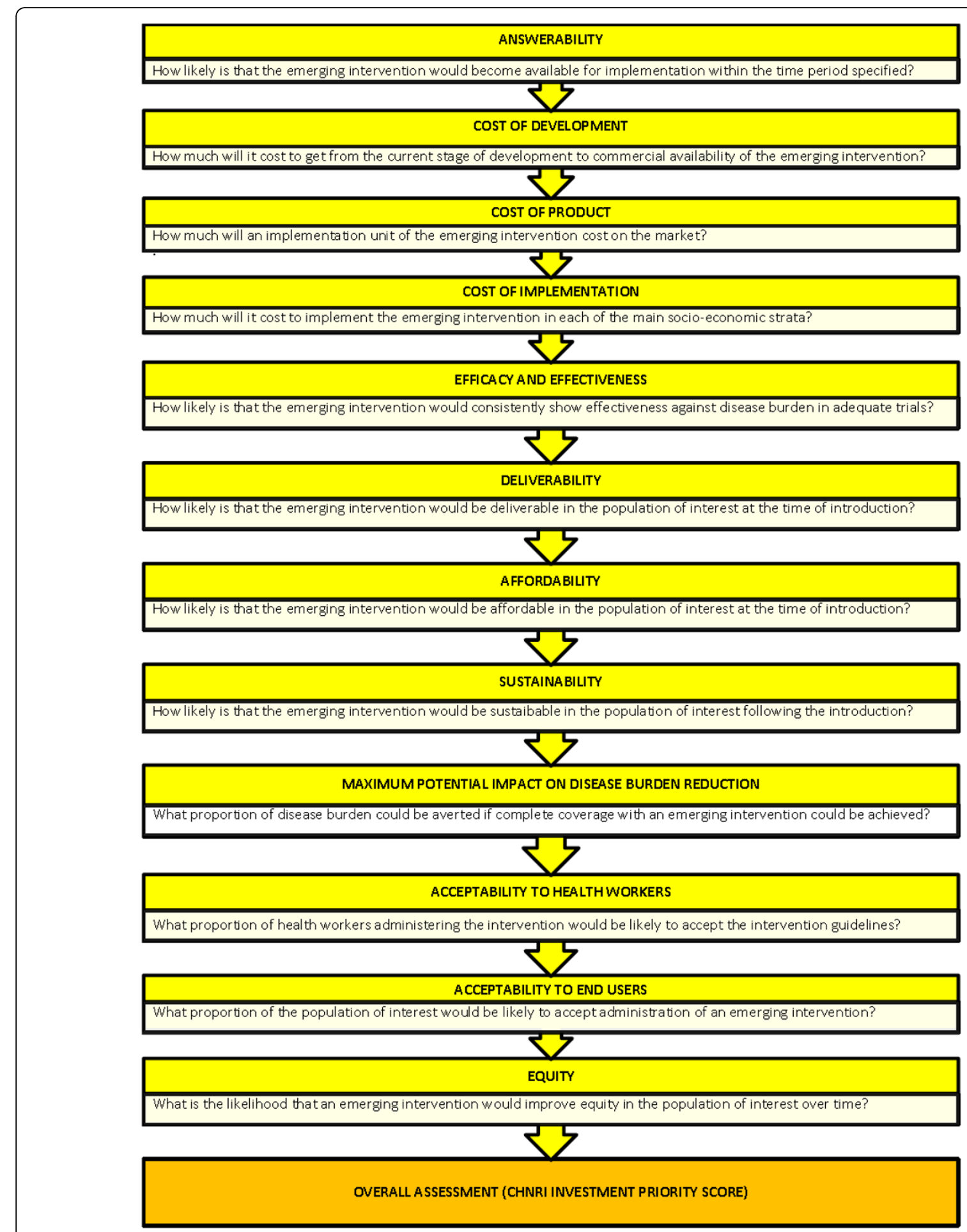

Figure 1 A summary of Stage I of the CHNRI process of evaluation of an emerging intervention (a systematic review of the key CHNRI criteria). CHNRI- Child Health and Nutrition Research Initiative. 


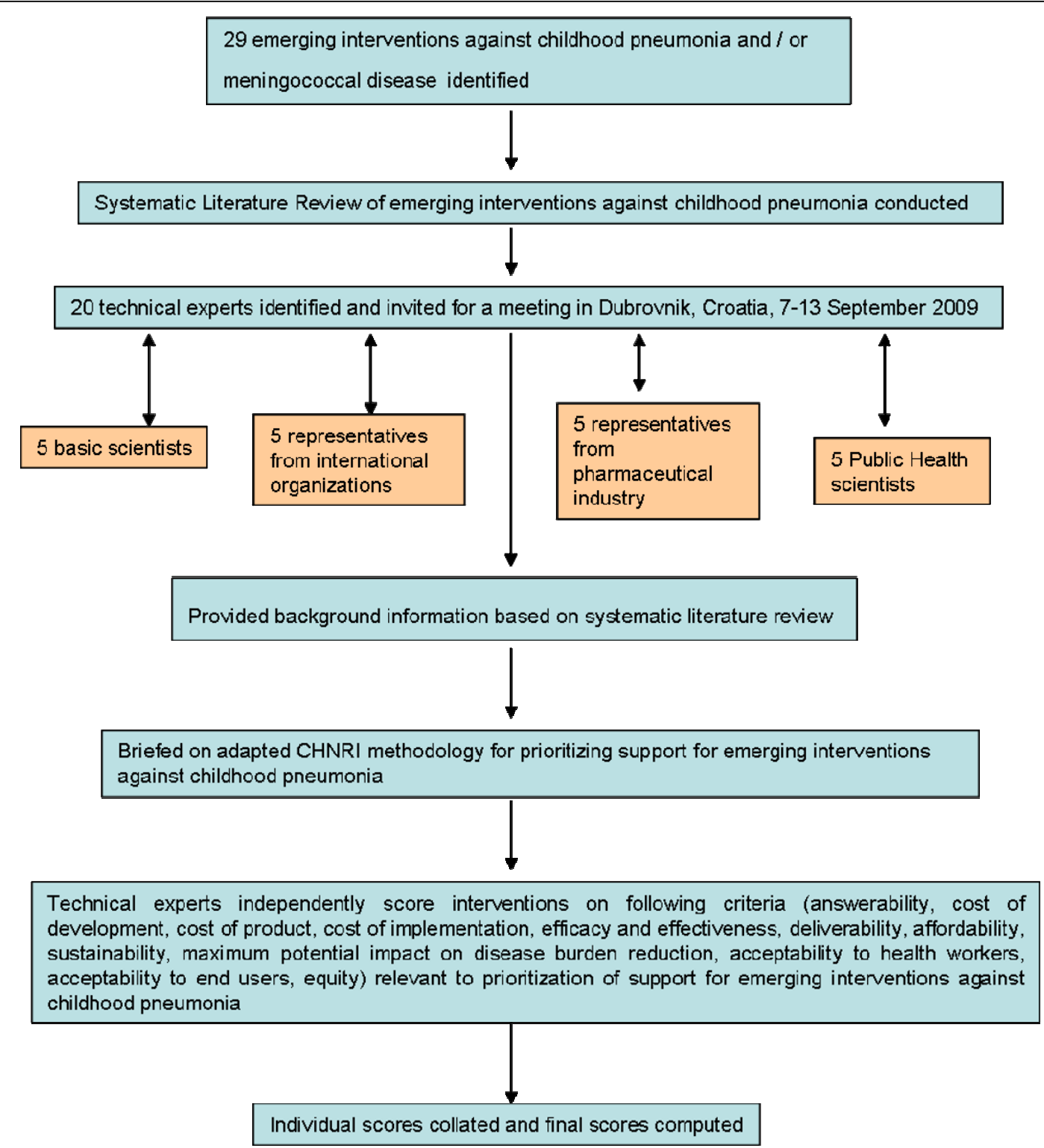

Figure 2 A summary of Stage II of the CHNRI process of evaluation of an emerging intervention (an expert opinion exercise using the CHNRI criteria). CHNRI- Child Health and Nutrition Research Initiative

vaccination will generate immunity both locally in the respiratory mucosa as well as systemically. In Eastern Europe thousands of people have been immunized via the respiratory mucosa, with live attenuated vaccine against many infectious agents including anthrax and small-pox [25].

One of the formulations of the aerosolized measles vaccine proposes to use the same formulation as the existing subcutaneous measles vaccine i.e. aerosolize the liquid formulation of the current injectable vaccine. By adopting this strategy, MAP has managed to avoid years of investigations in attempting to reformulate the vaccine constitution [26]. Consequently, the development process is limited to creating an innovative device which can deliver the vaccine in a way that elicits an antibody response of equivalent or greater immunogenicity to that of the current vaccine.

Research efforts are also underway to produce an inhalable dry powder vaccine. In one of these formulations, the weakened measles virus will be mixed with high-pressure carbon dioxide to produce microscopic bubbles and droplets, which will then be gently dried to produce an inhalable powder [27].

The existing vaccine product is a viable selection for application to the aerosol device as it has a high success rate of provoking good seroresponse. Over ninety five 
percent of infants seroconvert if the first dose of the measles vaccine was given at 9 months, and over 99 percent seroconvert if the first dose was given at or after 12 months [5]. The question is whether this response is transferable to an aerosolized delivery system.

Two methods for the delivery of liquid aerosol vaccines are currently under trial. The inflatable bag aerosol method, a concept introduced in 2009, has only completed proof of principle trials and has not yet entered pre-clinical trials. The nebulized aerosol method has completed phase I clinical trials and will shortly be entering phase II/III clinical trials.

Robert Sievers and colleagues who have invented and patented a device known as Carbon dioxoide Assisted Nebuilization with a Bubble Dryer (CAN-BD) in a presentation at the 238th National Meeting of the American Chemical Society (ACS) indicated that the dry powder measles vaccine (developed in collaboration with Serum Institute of India) will be ready for entry into phase I clinical trials in India in 2010 [27]. They have also developed a dry powder live attenuated measles vaccine which does not require reconstitution and have demonstrated the safety and efficacy of the vaccine in rhesus macaques [28].

Presented with these evidence, the panel of experts however expressed moderate levels of optimism (score around $60 \%$ ) concerning the ability of aerosolized measles to satisfy the criterion of answerability (Figure 3 ).

\section{Efficacy and effectiveness}

Liquid aerosolized measles vaccination has been evaluated in a multitude of field studies dating back over the last 30 years. The concept of an aerosolized vaccine was proven to be feasible in very early clinical trials carried out by Sabin et al. $[29,30]$. Following the results of these trials, several research groups, predominantly in Mexico and South Africa, pursued further research into measles aerosol vaccination. Results of major clinical and preclinical trials are outlined in Table 1 and Table 2 respectively.

Low and colleagues in a meta-analysis of results from 7 randomized trials, 4 non randomized trials, and 6 uncontrolled studies demonstrated that in the case of children aged below 10 months, subcutaneous measles vaccine showed a greater seroconversion rate compared to those using the aerosol route [24]. They suggested that this was perhaps partly due to persistent maternal antibodies (at this age) that interfered with the immune response and partly due to the poor suitability of the aerosol device for this age group. However, in children aged 10 months and older, aerosolized measles vaccine was found to be more immunogenic than the subcutaneous one. An earlier systematic review and meta-analysis by Hiremath and Omer in 2005 using data from 20 results from 16 studies concluded that the measles vaccine administered via respiratory route is as at least as immunogenic as subcutaneous vaccine [31]. Questions however remain regarding the optimal age for the first dose of the vaccine in high burden areas and the optimal number of doses required to achieve a sero-conversion rate above 95 percent in the population.

The nebulised aerosol measles vaccination entered stage I clinical trials in India in 2006. There, 60 subjects were assessed for their immunological responses at 3 different sites. The trial was due for completion in 2008, but no results have yet been published. Preliminary data suggest a low adverse event profile and good provocation of immunogenecity. Late stage clinical trials were due to commence in 2007, but at present there are no published data to ascertain the progress of the vaccine (Figure 4).

A recent "proof of principle" trial has been completed using inflatable bag and valved mask technology. The bags with 3-4 litre capacity were inflated with $0.053 \mathrm{ml}$ of vaccine in roughly 4 seconds, and inhaled until total collapse of the bag was seen. Data from this trial demonstrated almost double the number of children showing a 4-fold or 2-fold boosted antibody response when vaccinated via the inflatable bag than by injection. Though this model proposes to offer similar advantages to the nebulised formulation, it should be able to deliver a more measurable dose between individuals and hopes to offer greater protection in infants (Figure 4).

The dry powder vaccination has had a more protracted course of development (Figure 5). Although the limited studies on such formulation have all highlighted the plausibility of a marketable dry powder product, none of the published data through May 2009 showed a specific in vivo demonstration of clinical safety and efficacy (Table 3). Scientists in the United States have recently demonstrated that respiratory delivery of a single dose of dry powder live attenuated measles vaccine in rhesus macaques is capable of inducing durable fully protective immunity comparable to the injectable vaccine [28].

Presented with the evidence from the literature through May 2009 (Table 3), the panel of experts expressed concern (score around 50\%) regarding the ability of aerosolized measles vaccines to satisfy the criterion of efficacy (Figure 3).

\section{Deliverability, affordability and sustainability}

Deliverability refers to the prospects of an emerging intervention to overcome environmental and economical barriers to achieve high coverage, particularly in low resource settings. This criterion takes into account the level of difficulty with aerosolized measles vaccine delivery, the infrastructure and other resources 


\section{Aerosol measles vaccines}
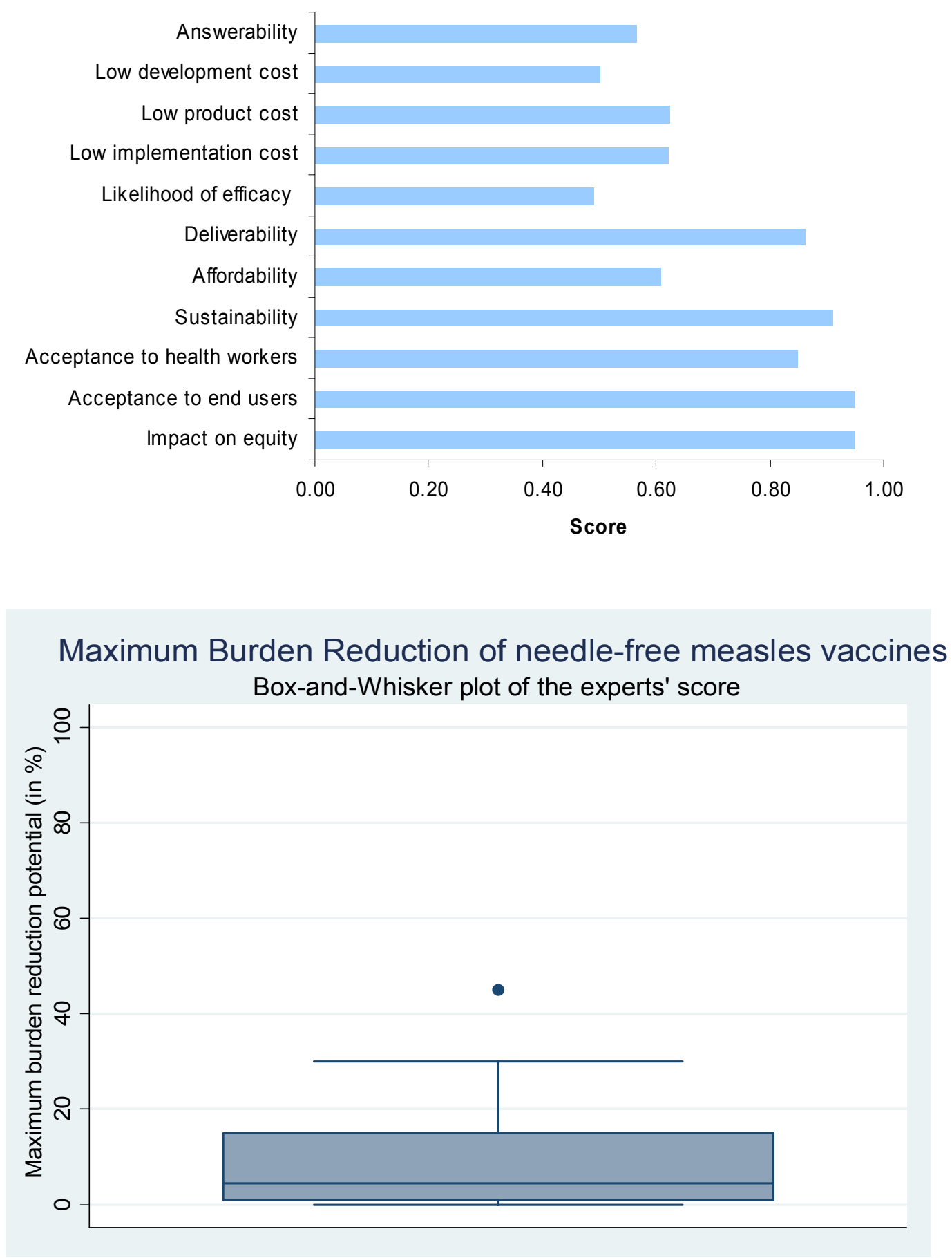

Figure 3 The results of Stage II of the CHNRI process - an expert opinion exercise assessing the potential usefulness of investment in needle-free measles vaccines. CHNRI- Child Health and Nutrition Research Initiative

available to implement the intervention and also government capacity and partnership requirements for achieving near-universal coverage with this new intervention. The aim of MAP (as well as other aerosol measles vaccine efforts) is also to develop a product that is primarily suitable for use in low resource environments, and is capable of quick implementation in mass campaigns. 
Table 1 Summary of major clinical trials on aerosol measles vaccines presented to the expert group for stage II of the CHNRI process

\begin{tabular}{|c|c|c|c|}
\hline Reference & MV Strain & Age group & Seroconversion as defined by authors \\
\hline A.Dilraj et al [46] & $\begin{array}{l}\text { MV-Schwarz (s/c, aerosol), } \\
\text { MV- Edmonston-Zagreb (s/c, } \\
\text { aerosol) }\end{array}$ & $\begin{array}{l}992 \\
\text { participants } \\
5-14 \text { years }\end{array}$ & $\begin{array}{l}\text { Seroconversion rates (defined as four fold increase in antibody level): } \\
\text { EZ Aerosol }-84.7 \% \\
\text { EZ sC }-78.8 \% \\
\text { SW Aerosol }-22.7 \% \\
\text { SW SC }-62.6 \%\end{array}$ \\
\hline A.Dilraj et al [47] & $\begin{array}{l}\text { MV-Schwarz (s/c), } \\
\text { MV- Edmonston-Zagreb (s/c, } \\
\text { aerosol) }\end{array}$ & $\begin{array}{l}337 \\
\text { participants } \\
5-14 \text { years }\end{array}$ & $\begin{array}{l}\text { Seroconversion (defined as four fold increase in antibody level) at } 6 \text { years } \\
\text { after revaccination: } \\
\text { EZ Aerosol - } 86 \% \\
\text { EZ sC }-73 \% \\
\text { SW sc }-58 \%\end{array}$ \\
\hline J.A.Bellanti et al [48] & $\begin{array}{l}\text { MV- Edmonston-Zagreb (s/c, } \\
\text { aerosol) }\end{array}$ & $\begin{array}{l}49 \\
\text { participants } \\
6-7 \text { years }\end{array}$ & $\begin{array}{l}\text { The mean Specific anti-measles lgG antibody: } \\
\text { EZ sC }-22.9 \pm 4.6 \\
\text { EZ aerosol }-53.4 \pm 9.4 \\
\text { Results are reported as mean _ } \mu \mathrm{g} / \mathrm{ml} \pm \text { standard error of the mean }\end{array}$ \\
\hline J.V.Bennett et al [49] & $\begin{array}{l}\text { MV-Schwarz (s/c), } \\
\text { MV- Edmonston-Zagreb (s/c, } \\
\text { aerosol) }\end{array}$ & $\begin{array}{l}1624 \\
\text { participants } \\
6-8 \text { years }\end{array}$ & $\begin{array}{l}\text { Change from seronegative to seropositive, }>=120 \mathrm{mlU} / \mathrm{ml} \\
\text { EZ aerosol }-65 \% \\
\text { EZ sc }-4 \% \\
\text { SW sc }-23 \%\end{array}$ \\
\hline $\begin{array}{l}\text { R.M.Wong-Chew et al } \\
\text { [50] }\end{array}$ & $\begin{array}{l}\text { MV- Edmonston-Zagreb (s/c, } \\
\text { aerosol) }\end{array}$ & $\begin{array}{l}114 \\
\text { participants } \\
11-13 \text { months }\end{array}$ & $\begin{array}{l}\text { Seroresponse rates as defined by four fold increase in antibody level: } \\
\text { EZ aerosol }-89.8 \% \\
\text { EZ sc }-100 \%\end{array}$ \\
\hline $\begin{array}{l}\text { R.M.Wong-Chew et al } \\
\text { [51] }\end{array}$ & $\begin{array}{l}\text { MV- Edmonston-Zagreb (s/c, } \\
\text { aerosol) }\end{array}$ & $\begin{array}{l}129 \\
\text { participants } \\
8-10 \text { months }\end{array}$ & $\begin{array}{l}\text { Seroresponse rates as defined by four fold increase in antibody level: } \\
\text { EZ Aerosol - } 42 \% \\
\text { EZ sC }-67 \%\end{array}$ \\
\hline
\end{tabular}

\section{Intervention}

The existing subcutaneous measles vaccine is associated with some safety risks. In the developing world unsafe needle practices put individuals at the risk of blood borne viral transmission, including hepatitis $C$ virus (HCV), hepatitis B virus (HBV) and human immunodeficiency virus (HIV) [32]. Unsafe injection practices comprise needle re-use, inefficient needle sterilization and improper needle waste disposal. In addition, needlestick injuries within the healthcare profession are not infrequent, carrying an equivalent risk of blood-borne virus transmission. Approximately 3 million health workers across the globe are injured by sharps contaminated with HBV, HCV or HIV annually [32]. The

Table 2 Summary of major pre-clinical trial studies of aerosol measles vaccines presented to the expert group for stage II of the CHNRI process

\begin{tabular}{|c|c|c|c|}
\hline Reference & $\begin{array}{l}\text { Factor for } \\
\text { investigation }\end{array}$ & Results & Comment \\
\hline $\begin{array}{l}\text { Low, N } \\
\text { et al } \\
\text { de Vries } \\
\text { et al } \\
{[24,35]}\end{array}$ & Vaccine strain & EZ > Schwarz in all studies. & $\begin{array}{l}\text { In South Africa, the Schwarz strain was inactivated as an } \\
\text { aerosol. }\end{array}$ \\
\hline $\begin{array}{l}\text { Laube, B.L } \\
{[26]}\end{array}$ & $\begin{array}{l}\text { Device } \\
\text { selection }\end{array}$ & $\begin{array}{l}3 \text { systems for entry at clinical trial: Un-vented, Breath- } \\
\text { enhanced \& Ultrasonic nebulizer. All models fulfil safety } \\
\text { and logistic criteria. }\end{array}$ & $\begin{array}{l}\text { Suitability criteria - portable, easy to use, battery-operated, } \\
\text { sanitary, operable with replacement parts. }\end{array}$ \\
\hline $\begin{array}{l}\text { Coates, } A \text {. } \\
L \text { et al[52] }\end{array}$ & $\begin{array}{l}\text { Viral particle } \\
\text { size }\end{array}$ & $\begin{array}{l}\text { Minimum }<10 \mu m \\
\text { Deep lung deposition }<5 \mu m\end{array}$ & Size of inhaled droplet is best determinant of lung deposition \\
\hline $\begin{array}{l}\text { Coates, } A . \\
L \text { et al[52] }\end{array}$ & $\begin{array}{l}\text { Number of } \\
\text { infective } \\
\text { particles }\end{array}$ & $\begin{array}{l}<1000 \text { pfu's; } 30-250 \text { pfu's required to stimulate } \\
\text { immune response }\end{array}$ & 5000 pfu's delivered in percutaneous measles vaccine \\
\hline $\begin{array}{l}\text { Cohen, B.J } \\
\text { et al[53] }\end{array}$ & $\begin{array}{l}\text { Potency } \\
\text { retention }\end{array}$ & $\begin{array}{l}85-102 \% \text { vaccine potency retention in all } 3 \text { measles } \\
\text { aerosol device's. }\end{array}$ & $\begin{array}{l}\text { Potential disaggregation of viral particles during aerosolization } \\
\text { accounts for results }>100 \%\end{array}$ \\
\hline $\begin{array}{l}\text { de Swart, } \\
\text { R. L et al } \\
{[54]}\end{array}$ & $\begin{array}{l}\text { Animal } \\
\text { model - } \\
\text { safety }\end{array}$ & $\begin{array}{l}\text { No superimposed risk in immunocompromised or } \\
\text { asthmatics. } \\
\text { No risk of vaccine-associated encephalitis or Bells palsy } \\
\text { identified. }\end{array}$ & $\begin{array}{l}\text { Concern of illness exacerbation in vulnerable groups. } \\
\text { Postulation of direct CNS contact through cribiform plate } \\
\text { precipitating neurological symptoms. }\end{array}$ \\
\hline
\end{tabular}




\section{Current Status}

\section{Pre-clinical $>$ Phase I $>P$ II $>P$ III $>P$ IV}

Liquid aerosol measles vaccination via inflatable bags and valved masks

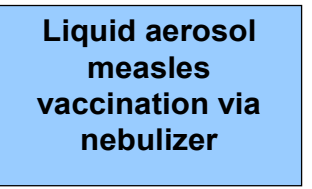

Figure 4 The current status of the research into measles aerosol vaccines presented to the expert group for stage II of the CHNRI process

nebulized device is designed to be easily administered. This should lower training requirements for individuals administering the measles vaccine [33]. Consequently, this should enable a wider span of vaccine delivery, with the potential to employ non-healthcare staff within rural communities to distribute and deliver the vaccine. This would significantly ease pressures on under-staffed health care systems, such as most of those in the developing world. The oral polio vaccination campaign is one good example of such vaccination strategies implemented using non-medical personnel [34]. Furthermore, this would reduce the overall cost of the program. However, a standard dose of aerosolised vaccine is inhaled over 30 seconds with minimal preparation time [35]. Because of this, an increased health worker contact time is anticipated. This may result in lesser number of vaccinations delivered each day, which could undermine mass vaccination campaigns when very large numbers of children need to be immunized.

\section{Expanded program on immunization}

The new intervention would fit into the current Expanded Program on Immunization (EPI) schedule. Guidelines for measles vaccination of infants at 9 months exist in countries with high disease burden for measles. In countries where measles vaccine uptake is high, children are routinely immunized between 9 and 12 months [36]. The Working Group on Measles
(WGM) recommends a second measles dose (MCV2) in countries which achieve over $75 \%$ vaccine coverage of MCV1. SIAs are encouraged every 2-4 years, used as either follow-up or catch-up programmes, targeting children born since the last campaign. They allow for children, who have missed their measles vaccination through the national immunization schedule, to have another opportunity for vaccination. From 2000 to 2007, 576 million children between 9 months and 14 years of age were vaccinated against measles through SIAs [4].

\section{Infrastructure}

Cold chain has a limited coverage and integrity in developing countries, resulting in restrictions on vaccine distribution [37]. The existing measles vaccine is relatively thermo stable prior to reconstitution [38]. After reconstitution, the vaccine must be discarded of within 6 hours due to risks of potency loss and contamination. Heat damage occurs through interruptions in the cold chain or heat shock to the vaccine from the addition of a warm diluent [38].

The liquid aerosol measles vaccine demands no alteration to the existing measles cold chain requirements. However, more space may be required to store the delivery device. Limited storage space is an issue in many developing countries. The dry powder formulation proposes to eliminate cold chain requirements. The potency of the dried vaccine was tested and the results 


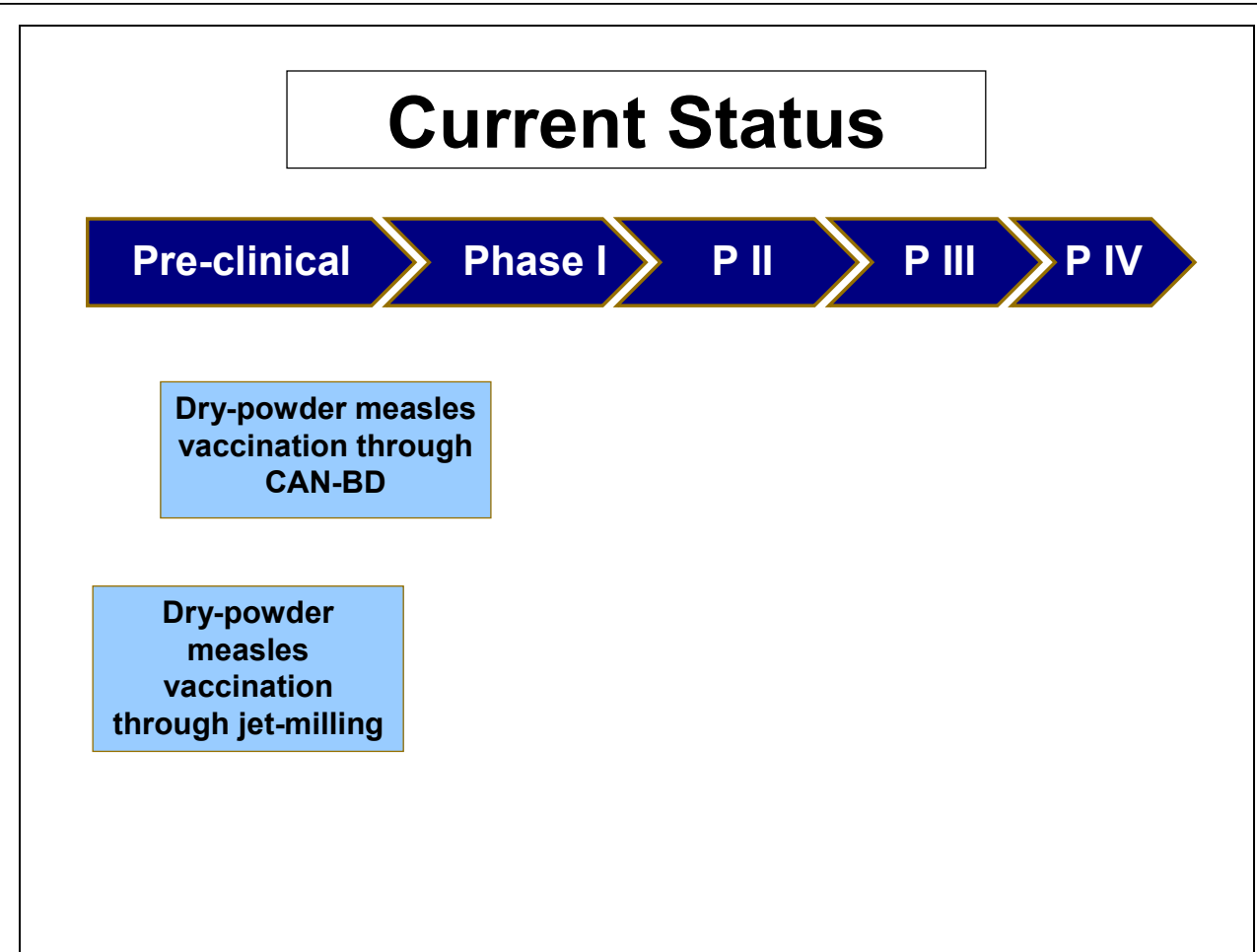

Figure 5 The current status of the research into measles dry powder product presented to the expert group for stage II of the CHNRI process

showed that the dry-powdered aerosol was stable for at least eight weeks at $37^{\circ} \mathrm{C}$ [27]. Cold chain facilities maintenance costs are approximately $\$ 200-300$ million annually [32] and are responsible for almost one third of the UNICEF's annual budget for immunization [39]. If research could be directed at producing more vaccines that did not require cold chain, vast savings could be made. Additionally, without the limitations of cold chain, the vaccine could be stored for expansive lengths of time without degeneration and could be further distributed to remote areas with no cold chain facilities.
Based on these evidence, the panel of experts expressed high levels of optimism (score around 80\%) regarding the deliverability of the aerosolized measles vaccine (Figure 3).

\section{Cost}

MAP receives financial and technical support from several agencies, most notably the Bill and Melinda Gates Foundation, the American Red Cross, the WHO and the US Centers for Disease Control and Prevention. Generally, measles is a relatively under-funded disease for

Table 3 Summary of studies of dry powder measles product presented to the expert group for stage II of the CHNRI process

\begin{tabular}{|c|c|c|c|}
\hline Reference & $\begin{array}{l}\text { Factor for } \\
\text { investigation }\end{array}$ & Results & Conclusions \\
\hline $\begin{array}{l}\text { LiCalsi, C., } \\
\text { et al } \\
{[55]}\end{array}$ & $\begin{array}{l}\text { Feasibility of dry } \\
\text { powder inhalation } \\
\text { in measles }\end{array}$ & $\begin{array}{l}\text { Optimal vaccine delivery site - lungs; Particle sizing 1- } \\
5 \mu m ; \text { Preparation - micronization and jet-milling ;3 } \\
\text { Spiros delivery devices designed }\end{array}$ & Undemonstrable clinical application \\
\hline $\begin{array}{l}\text { de Swart, } \\
\text { R.L., et al } \\
{[56]}\end{array}$ & $\begin{array}{l}\text { Dry powder } \\
\text { vaccination in } \\
\text { Macaques }\end{array}$ & $\begin{array}{l}\text { Low seroresponse to measles dry powder blend } \\
\text { compared to injection or liquid aerosol vaccination }\end{array}$ & $\begin{array}{l}\text { Proof of principle evident by stimulation of weak } \\
\text { immune response. Poor device design in macaque } \\
\text { model - loss of vaccine at delivery. }\end{array}$ \\
\hline $\begin{array}{l}\text { LiCalsi, C., } \\
\text { et al } \\
{[57]}\end{array}$ & $\begin{array}{l}\text { Dry powder } \\
\text { measles vaccine } \\
\text { potency retention }\end{array}$ & $\begin{array}{l}\text { Up to } 89 \% \text { viral potency retention can be achieved with } \\
\text { micronization. }\end{array}$ & \\
\hline $\begin{array}{l}\text { Burger, } \\
\text { J.L., et al } \\
{[58]}\end{array}$ & $\begin{array}{l}\text { Stabilizing dry } \\
\text { powder measles } \\
\text { formulations }\end{array}$ & $\begin{array}{l}\text { Myo-inositol> trehalose as a sugar stabilizer in dry } \\
\text { powder measles vaccinations }\end{array}$ & $\begin{array}{l}\text { Myo-inositol is relatively unhygroscopic, improving its } \\
\text { dry powder vaccination credentials }\end{array}$ \\
\hline
\end{tabular}


which the funding gap stood at $\$ 176$ million for the year 2009-2010 [4]. The existing measles delivery system is affordably priced at $\$ 0.06$ per dose. While the aerosol device itself is more expensive, savings are expected to be noticed in the returns gained from diminished blood borne virus transmission. A recent cost-analysis model estimated that the societal cost of inappropriate needle use leading to blood borne virus transmission totals $\$ 26.77$ per injection [40]. It is presumed that, based on this model, there will be cost-savings of an aerosol device when the wider connotations of the current vaccine are factored in. A review assessing the potential economic impact of introducing a thermo-stable vaccine in Cambodia, Bangladesh and Ghana predicted its high cost-effectiveness in all three countries [41]. Savings would be made through reduced vaccine wastage, the avoidance of adverse events from unsafe needle practice, as well as savings from the subtracted cold chain requirements [32]. Presented with these evidence, the panel of experts expressed concerns (score around 50\%) over the ability to develop a low-cost aerosolized vaccine. However, given the very high level of interest in the MAP from various funding agencies, the group felt moderately optimistic (score around 60 percent) regarding possiblity to make the vaccine available at a lower price to the consumers in developing countries. They also were moderately optimistic (score around 60 percent) that the production and implementation cost of the vaccine could be kept low. The low pricing should also be sustainable, given the high level of commitment of many donors towards measles elimination programme (Figure 3).

\section{Local and context-specific factors}

Health systems of all developing nations are not homogeneous and therefore cannot be expected to show exactly the same response in regards to all factors related to deliverability of any health intervention [42]. Unstable political environment, civil war and natural disasters are examples of circumstances which can drastically interfere with the distribution of even the most cost-effective healthcare strategies. Measles control in the Eastern Mediterranean region has been plagued with slow progress due to turbulent political climate in a number of countries [4]. The deliverability factors discussed here would have their highest index of impact only if a strong political leadership and commitment could be generated.

\section{Maximum potential for disease burden reduction}

"Disease burden reduction" considers whether there will be a significant percentage decrease in global measles mortality (mainly due to the complication of severe pneumonia) with the introduction of the newly proposed interventions. In 2008, approximately 164,000 individuals died as a consequence of measles despite considerable efforts to prevent and control disease outbreaks. Over $90 \%$ of these deaths were estimated to have been in children aged below 5 years [4]. Urbanization and rapid population growth pose special challenges for measles eradication since they facilitate person-to-person spread of the highly contagious measles virus; experience shows that these conditions require sustained immunization coverage levels of $>95 \%$ to interrupt transmission. The WHO region of Americas has eliminated measles transmission using the supplementatary immunization activities targeting children aged 9 months to 14 years to quickly raise immunization coverage to $\geq 95$ percent [5]. In $2007,65 \%$ of children not receiving their first dose of measles vaccine came from only 8 countries: India, Nigeria, China, Ethiopia, Indonesia, Pakistan, the Democratic Republic of Congo and Bangladesh [7]. This demonstrates that the barrier to elimination and eradication of measles is not in the vaccine per se but in its delivery. Hence, greater investments in either improvement of existing intervention strategies to increase coverage or identifying new delivery mechanisms are needed $[5,43]$.

A study of vaccination in Mongolia indicated that vaccines that reach rural communities suffer increased breaks in the cold chain, exposing the vaccine to unsuitable temperatures. Consequentially, rural children exhibited lower antibody response than urban children [44]. With the dry powder measles vaccine formulation, the cold chain requirements can be obviated and therefore there is a possibility for even wider immunization coverage by improved access to marginalised communities and those residing in remote and hard to reach areas resulting in greater decline in disease burden. Based on these evidence and their experience in developing countries, the panel of experts felt that the aerosolized measles vaccine would have modest levels of maximum impact on overall pneumonia disease burden (median: $5 \%$, interquartile range $1-15 \%$, minimum $0 \%$, maximum $45 \%$ ) when compared to the existing measles vaccine (Figure 3 ).

\section{Equity}

The assessment of a vaccine according to "equitability" takes into account the predicted effects that implementation of the new technology will have on poor populations within countries. The score is high when the experts agree that the resultant impact will reduce health inequities between rich and poor social groups. The highest impact of measles mortality is on the poorest communities in the world [7]. The aim of introducing a novel intervention is to target this section of society in order to decrease health inequities. In Latin America, measles has been the target of a large scale 
intervention programme to try and eliminate the disease [43]. In a region with very large disparities in economic wealth, an equitable response to the programme was achieved by all nations, demonstrating that the "...successful implementation of immunization strategies is more important to achieve elimination than the underlying socio-demographic circumstances of the country" [36].

The greatest uptake of an intervention is amongst the highest social groups, with the lowest social classes suffering from diminished intervention coverage, weaker health services and greater disease exposure. This is liable to continue to be the case for any new intervention which does not aim to tackle the distributive factors, and which fits the same format as the existing technologies. In the case of novel interventions, such as the measles aerosol vaccine, there is the potential to counteract this monotonous pattern of uptake especially using SIAs which target the vulnerable and marginalised communities in developing countries. Disparities in the coverage of immunization between the rich and poor are reduced relative to other interventions. This suggests that investing in immunization as a health strategy is advantageous as the uptake across the spectrum of society is close to indifferent and therefore there will be a reduced gradient of health inequity [45]. The panel expressed very high levels of optimism (score over 90\%) regarding the ability of the aerosolized measles vaccine to have a positive impact on equity (Figure 3 ).

\section{Acceptability to end users}

Mothers claimed to prefer the needle-free route in early measles aerosol clinical trials held in Mexico [11]. Pain and phobic associations with needle-syringe delivery systems are the main limiting factors and they result in reduced compliance with injectable measles vaccine. Since the attitudes of parents (with regard to injectable vaccines) are largely similar across the globe, it may not be incorrect to generalise the results. However, community based trials or post licensure field effectiveness trials will be needed to assess the safety and acceptability of aerosol based vaccines more formally. The experts were very optimistic (score over $80 \%$ ) that the vaccine would be acceptable to both the end-users and health workers (Figure 3).

\section{Discussion}

Measles is an important risk factor for childhood pneumonia and thus is responsible for a large proportion of pneumonia associated mortality in young children especially in low and middle-income countries where the disease burden due to measles continues to be high. Although an effective measles vaccine exists, there are operational challenges concerning the delivery of the vaccine to achieve universal coverage. The literature review summarized in this paper presents the evidence required for making an informed decision on the research priority that should be given to aerosolized measles vaccine to reduce the burden of childhood pneumonia. The scores for the liquid and dry powder formulations of the inhalable measles vaccine against the set criteria represent the collective optimism of a panel of experts drawn from varying technical backgrounds and affiliations. Although there is currently no licensed aerosolized measles vaccine, significant progress is being made for developing one such vaccine.

Intensification of the measles vaccination programme over the past decade has helped to dramatically reduce the global disease burden due to measles and thus the childhood pneumonia mortality. However, the rate of decline in measles mortality is unlikely to continue at the same level for long. In order to sustain and enhance the gains made in reducing the disease burden associated with measles, some new approaches are needed. In Latin America, scaling up of existing vaccination services in order to decrease the number of measles cases across the region has been a very successful strategy [4]. This case of strengthening the investments in existing vaccination programmes should be acknowledged as a prospective strategy to be applied in other regions of the world.

However, investment in novel vaccinations may offer a promising mode of challenging currently limiting deliverability factors. In the case of candidate aerosolized measles vaccines, the experts expressed low levels of optimism regarding the criteria of likelihood of efficacy, low cost of development and modest impact on reducing the burden of childhood pneumonia; moderate levels of optimism regarding answerability, low cost of production, low cost of implementation and affordability; and high levels of optimism regarding deliverability, sustainability, impact on equity and acceptability to health workers and end-users. Further research is needed to establish the safety and optimal age for primary vaccination using aersolized measles vaccine. The liquid aerosol vaccination needs to undergo more trials in children aged less than 5 years as the majority of immunization successes are demonstrated in older children. Efficient post-licensure surveillance systems need to be put in place to monitor coverage and ensure reporting of adverse that adverse following immunization. For an optimal dry powder measles vaccination product, it is important that along with assessment of safety and effectiveness of the vaccine, the maximal device outputs be calculated before entry into the clinical trial process.

This is the first time such an exercise has been conducted with the aim of predicting the future impact of 
emerging vaccines on childhood pneumonia. The CHNRI methodology was primarily designed to evaluate existing interventions and competing investment priorities for health research. Even though we used the CHNRI criteria, we modified it by including systematic review of available literature and not involving all stakeholders (e.g. end-users and health workers). The scores reported in this paper express the collective opinion of a panel of 20 experts. Although this could be pointed out as a limitation, the main strengths of this approach are that it aims to be objective, systematic, evidence based and explicit.

\section{Conclusions}

To summarize, aerosolized measles vaccine presents an unique opportunity to not only control and eliminate measles morbidity and mortality in young children, but also decrease the overall burden of disease due to severe pneumonia in young children. Although there has been considerable progress in achieving the vision of effectively delivering measles vaccine through the respiratory route, it will still be a few years before such a vaccine is ready to be incorporated into the routine EPI programmes in high disease burden areas.

\section{Additional material}

Additional file 1: Supplementary tables: Supplementary Table 1: Details of search strategy for identifying studies reporting aerosolised measles vaccine Supplementary Table 2: Questions used in the Phase II CHNRI process.

\begin{abstract}
Acknowledgements
This work was supported by the grant from the Bill and Melinda Gates Foundation No. 51285 ("Modelling the impact of emerging interventions against pneumonia").

This article has been published as part of BMC Public Health Volume 11 Supplement 3, 2011: Technical inputs, enhancements and applications of the Lives Saved Tool (LiST). The full contents of the supplement are available online at http://www.biomedcentral.com/1471-2458/11?issue=\$3.

\section{Author details \\ ${ }^{1}$ Centre for Population Health Sciences, Global Health Academy, The University of Edinburgh, UK. ² Public Health Foundation of India, New Delhi, India. ${ }^{3}$ International Centre for Diarrhoeal Disease Research, Bangladesh (ICDDR,B), Dhaka, Bangladesh. ${ }^{4}$ Serum Institute of India Limited, Pune, India. ${ }^{5}$ Emory University, Rollins School of Public Health, Atlanta, GA, USA. ${ }^{6}$ Croatian Centre for Global Health, University of Split Medical School, Croatia.}

\section{Authors' contributions}

$\mathrm{DH}, \mathrm{HN}$ and $\mathrm{TH}$ were responsible for the acquisition of the data and conducted the literature review. ET, HN and LZ helped design the study's analytic strategy and prepared the Materials and Methods, Results and Discussion sections of the text. SSJ and SBO critically reviewed and revised the manuscript for important intellectual content. HN carried out the final revisions. $\mathrm{HC}$ and IR designed the study and provided guidance in analysis and writing of the manuscript. All authors read and approved the final manuscript.

\section{Competing interests}

$\mathrm{DH}, \mathrm{ET}, \mathrm{HN}, \mathrm{TH}, \mathrm{LZ}, \mathrm{SBO}, \mathrm{IR}$ and $\mathrm{HC}$ declare that they have no competing interests. SSJ is employed by Serum Institute of India Ltd. which has codeveloped the liquid and dry powder aerosol measles vaccines.

\section{Published: 13 April 2011}

\section{References}

1. Measles vaccines: WHO position paper. Wkly Epidemiol Rec 2009, 84(35):349-360.

2. Black RE, Cousens S, Johnson HL, Lawn JE, Rudan I, Bassani DG, Jha P, Campbell H, Walker CF, Cibulskis R, Eisele T, Liu L, Mathers C: Global, Regional and National Causes of Child Mortality, 2008. Lancet 2010.

3. Duke T, Mgone CS: Measles: not just another viral exanthem. Lancet 2003, 361(9359):763-773

4. World Health Organisation, Global elimination of measles report by the secretariat. [http://apps.who.int/gb/ebwha/pdf_files/EB125/B125_4-en.pdf].

5. Meeting of the International Task Force for Disease Eradication, June 2009. Wkly Epidemiol Rec 2009, 84(44):459-466.

6. Katz SL, John F: Enders and measles virus vaccine-a reminiscence. Curr Top Microbiol Immunol 2009, 329:3-11.

7. Progress in global measles control and mortality reduction, 2000-2007. Wkly Epidemiol Rec 2008, 83(49):441-448.

8. Levine MM: Can needle-free administration of vaccines become the norm in global immunization? Nat Med 2003, 9(1):99-103.

9. Sabin AB: Immunization against measles by aerosol. Rev Infect Dis 1983, 5(3):514-523.

10. Valdespino-Gomez JL, de Lourdes Garcia-Garcia M, Fernandez-de-Castro J, Henao-Restrepo AM, Bennett J, Sepulveda-Amor J: Measles aerosol vaccination. Curr Top Microbiol Immunol 2006, 304:165-193.

11. Fernandez-de Castro J, Kumate-Rodriguez J, Sepulveda J, Ramirez-Isunza JM, Valdespino-Gomez JL: Measles vaccination by the aerosol method in Mexico. Salud Publica Mex 1997, 39(1):53-60.

12. World Health Organisation, Measles aerosol project. [http://www.who.int/ immunization_delivery/new_vaccines/technologies_aerosol/en/].

13. Kapiriri L, Tomlinson M, Chopra M, El Arifeen S, Black RE, Rudan I: Setting priorities in global child health research investments: addressing values of stakeholders. Croat Med J 2007, 48(5):618-627.

14. Rudan I: The complex challenge of setting priorities in health research investments. Indian J Med Res 2009, 129(4):351-353.

15. Rudan I, Chopra M, Kapiriri L, Gibson J, Ann Lansang M, Carneiro I, Ameratunga S, Tsai AC, Chan KY, Tomlinson M, Hess SY, Campbell H, El Arifeen S, Black RE: Setting priorities in global child health research investments: universal challenges and conceptual framework. Croat Med J 2008, 49(3):307-317.

16. Rudan I, El Arifeen S, Black RE, Campbell H: Childhood pneumonia and diarrhoea: setting our priorities right. Lancet Infect Dis 2007, 7(1):56-61.

17. Rudan I, Gibson J, Kapiriri L, Lansang MA, Hyder AA, Lawn J, Darmstadt GL, Cousens S, Bhutta ZA, Brown KH, Hess SY, Black M, Gardner JM, Webster J, Carneiro I, Chandramohan D, Kosek M, Lanata CF, Tomlinson M, Chopra M, Ameratunga S, Campbell H, El Arifeen S, Black RE: Setting priorities in global child health research investments: assessment of principles and practice. Croat Med J 2007, 48(5):595-604.

18. Bahl R, Martines J, Ali N, Bhan MK, Carlo W, Chan KY, Darmstadt GL, Hamer DH, Lawn JE, McMillan DD, Mohan P, Paul V, Tsai AC, Victora CG, Weber MW, Zaidi AK, Rudan I: Research priorities to reduce global mortality from newborn infections by 2015. Pediatr Infect Dis J 2009, 28(1 Suppl):S43-48

19. Fontaine O, Kosek M, Bhatnagar S, Boschi-Pinto C, Chan KY, Duggan C, Martinez H, Ribeiro H, Rollins NC, Salam MA, Santosham M, Snyder JD, Tsai AC, Vargas B, Rudan I: Setting research priorities to reduce global mortality from childhood diarrhoea by 2015. PLoS Med 2009, 6(3):e41.

20. Rudan I, Gibson JL, Ameratunga S, El Arifeen S, Bhutta ZA, Black M, Black RE, Brown KH, Campbell H, Carneiro I, Chan KY, Chandramohan D, Chopra M, Cousens S, Darmstadt GL, Meeks Gardner J, Hess SY, Hyder AA, Kapiriri L, Kosek M, Lanata CF, Lansang MA, Lawn J, Tomlinson M, Tsai AC, Webster J: Setting priorities in global child health research investments: guidelines for implementation of CHNRI method. Croat Med J 2008, 49(6):720-733. 
21. Tomlinson M, Chopra M, Sanders D, Bradshaw D, Hendricks M, Greenfield D, Black RE, El Arifeen S, Rudan I: Setting priorities in child health research investments for South Africa. PLoS Med 2007, 4(8):e259

22. Tomlinson M, Rudan I, Saxena S, Swartz L, Tsai AC, Patel V: Setting priorities for global mental health research. Bull World Health Organ 2009, 87(6):438-446.

23. Tomlinson M, Swartz L, Officer A, Chan KY, Rudan I, Saxena S: Research priorities for health of people with disabilities: an expert opinion exercise. Lancet 2009, 374(9704):1857-1862.

24. Low N, Kraemer S, Schneider M, Restrepo AM: Immunogenicity and safety of aerosolized measles vaccine: systematic review and meta-analysis. Vaccine 2008, 26(3):383-398.

25. Cutts FT, Clements CJ, Bennett JV: Alternative routes of measles immunization: a review. Biologicals 1997, 25(3):323-338.

26. Laube BL: The expanding role of aerosols in systemic drug delivery, gene therapy, and vaccination. Respir Care 2005, 50(9):1161-1176

27. American Association of Pharmaceutical Scientists: New Vaccine Delivery May Be More Effective Against Measles. ScienceDaily 2009, Retrieved November 1, 2009, from http://www.sciencedaily.com/releases/2009/09/ 090928172526.htm

28. Lin WH, Griffin DE, Rota PA, Papania M, Cape SP, Bennett D, Quinn B, Sievers RE, Shermer C, Powell K, Adams RJ, Godin S, Winston S: Successful respiratory immunization with dry powder live-attenuated measles virus vaccine in rhesus macaques. Proc Natl Acad Sci U S A 2011, 108(7):2987-2992.

29. Sabin AB, Flores Arechiga A, Fernandez de Castro J, Albrecht P, Sever JL, Shekarchi I: Successful immunization of infants with and without maternal antibody by aerosolized measles vaccine. II. Vaccine comparisons and evidence for multiple antibody response. Jama 1984, 251(18):2363-2371.

30. Sabin AB, Flores Arechiga A, Fernandez de Castro J, Sever JL, Madden DL, Shekarchi I, Albrecht P: Successful immunization of children with and without maternal antibody by aerosolized measles vaccine. I. Different results with undiluted human diploid cell and chick embryo fibroblast vaccines. Jama 1983, 249(19):2651-2662.

31. Hiremath GS, Omer SB: A meta-analysis of studies comparing the respiratory route with the subcutaneous route of measles vaccine administration. Hum Vaccin 2005, 1(1):30-36.

32. Giudice EL, Campbell JD: Needle-free vaccine delivery. Adv Drug Deliv Rev 2006, 58(1):68-89.

33. Global Vaccine Research Forum - Measles Aerosol Project. [http://www who.int/vaccine_research/about/gvrf/Greco_presentation.pdf].

34. Fine PE: Poliomyelitis: very small risks and very large risks. Lancet Neurol 2004, 3(12):703.

35. de Vries RD, Stittelaar KJ, Osterhaus AD, de Swart RL: Measles vaccination: new strategies and formulations. Expert Rev Vaccines 2008, 7(8):1215-1223.

36. World Health Organisation: Report on the 1st meeting of the SAGE working group on measles.[http://www.who.int/immunization/sage/ Final_report_1st_mtg_SAGE_WG_Measles.pdf].

37. Wirkas T, Toikilik S, Miller N, Morgan C, Clements CJ: A vaccine cold chain freezing study in PNG highlights technology needs for hot climate countries. Vaccine 2007, 25(4):691-697.

38. Chen D, Kristensen D: Opportunities and challenges of developing thermostable vaccines. Expert Rev Vaccines 2009, 8(5):547-557.

39. Matthias DM, Robertson J, Garrison MM, Newland S, Nelson C: Freezing temperatures in the vaccine cold chain: a systematic literature review. Vaccine 2007, 25(20):3980-3986.

40. Ekwueme DU, Weniger BG, Chen RT: Model-based estimates of risks of disease transmission and economic costs of seven injection devices in sub-Saharan Africa. Bull World Health Organ 2002, 80(11):859-870.

41. Levin A, Levin C, Kristensen D, Matthias D: An economic evaluation of thermostable vaccines in Cambodia, Ghana and Bangladesh. Vaccine 2007, 25(39-40):6945-6957.

42. Ranson MK, Kara H, Valeria O-C, Anne M: Constraints to expanding access to health interventions: an empirical analysis and country typology. Journal of International Development 2003, 15(1):15-39.

43. De Quadros CA, Izurieta H, Carrasco P, Brana M, Tambini G: Progress toward measles eradication in the region of the Americas. $J$ Infect Dis 2003, 187(Suppl 1):S102-110
44. Edstam JS, Dulmaa N, Nymadawa P, Rinchin A, Khulan J, Kimball AM: Comparison of hepatitis $B$ vaccine coverage and effectiveness among urban and rural Mongolian 2-year-olds. Prev Med 2002, 34(2):207-214.

45. Gwatkin DR, Bhuiya A, Victora CG: Making health systems more equitable. Lancet 2004, 364(9441):1273-1280.

46. Dilraj A, Cutts FT, de Castro JF, Wheeler JG, Brown D, Roth C, Coovadia HM, Bennett JV: Response to different measles vaccine strains given by aerosol and subcutaneous routes to schoolchildren: a randomised trial. Lancet 2000, 355(9206):798-803.

47. Dilraj A, Sukhoo R, Cutts FT, Bennett JV: Aerosol and subcutaneous measles vaccine: measles antibody responses 6 years after revaccination. Vaccine 2007, 25(21):4170-4174.

48. Bellanti JA, Zeligs BJ, Mendez-Inocencio J, Garcia-Garcia ML, Islas-Romero R, Omidvar B, Omidvar J, Kim G, Fernandez De Castro J, Sepulveda Amor J, Walls L, Bellini WJ, Valdespino-Gomez JL: Immunologic studies of specific mucosal and systemic immune responses in Mexican school children after booster aerosol or subcutaneous immunization with measles vaccine. Vaccine 2004, 22(9-10):1214-1220.

49. Bennett JV, Fernandez de Castro J, Valdespino-Gomez JL, Garcia-Garcia Mde L, Islas-Romero R, Echaniz-Aviles G, Jimenez-Corona A, SepulvedaAmor J: Aerosolized measles and measles-rubella vaccines induce better measles antibody booster responses than injected vaccines: randomized trials in Mexican schoolchildren. Bull World Health Organ 2002, 80(10):806-812.

50. Wong-Chew RM, Islas-Romero R, Garcia-Garcia Mde L, Beeler JA, Audet S, Santos-Preciado Jl, Gans H, Lew-Yasukawa L, Maldonado YA, Arvin AM, Valdespino-Gomez JL: Induction of cellular and humoral immunity after aerosol or subcutaneous administration of Edmonston-Zagreb measles vaccine as a primary dose to 12-month-old children. J Infect Dis 2004, 189(2):254-257.

51. Wong-Chew RM, Islas-Romero R, Garcia-Garcia Mde L, Beeler JA, Audet S, Santos-Preciado II, Gans H, Lew-Yasukawa L, Maldonado YA, Arvin AM, Valdespino-Gomez JL: Immunogenicity of aerosol measles vaccine given as the primary measles immunization to nine-month-old Mexican children. Vaccine 2006, 24(5):683-690.

52. Coates AL, Tipples G, Leung K, Gray M, Louca E: How many infective viral particles are necessary for successful mass measles immunization by aerosol? Vaccine 2006, 24(10):1578-1585.

53. Cohen BJ, Parry RP, Andrews N, Bennett AM, Dennis JH: Laboratory methods for assessing vaccine potency retained in aerosol outputs from nebulizers: application to World Health Organization measles aerosol project. Vaccine 2008, 26(27-28):3534-3539.

54. de Swart RL, Kuiken T, Fernandez-de Castro J, Papania MJ, Bennett JV, Valdespino JL, Minor P, Witham CL, Yuksel S, Vos H, van Amerongen G, Osterhaus AD: Aerosol measles vaccination in macaques: preclinical studies of immune responses and safety. Vaccine 2006, 24(4041):6424-6436.

55. LiCalsi C, Christensen T, Bennett JV, Phillips E, Witham C: Dry powder inhalation as a potential delivery method for vaccines. Vaccine 1999, 17(13-14):1796-1803.

56. de Swart RL, LiCalsi C, Quirk AV, van Amerongen G, Nodelman V, Alcock R Yuksel S, Ward GH, Hardy JG, Vos H, Witham CL, Grainger Cl, Kuiken T, Greenspan BJ, Gard TG, Osterhaus AD: Measles vaccination of macaques by dry powder inhalation. Vaccine 2007, 25(7):1183-1190.

57. LiCalsi C, Maniaci MJ, Christensen T, Phillips E, Ward GH, Witham C: A powder formulation of measles vaccine for aerosol delivery. Vaccine 2001, 19(17-19):2629-2636.

58. Burger JL, Cape SP, Braun CS, McAdams DH, Best JA, Bhagwat P, Pathak P, Rebits LG, Sievers RE: Stabilizing formulations for inhalable powders of live-attenuated measles virus vaccine. I Aerosol Med Pulm Drug Deliv 2008, 21(1):25-34.

doi:10.1186/1471-2458-11-S3-S31

Cite this article as: Higginson et al: An evaluation of respiratory administration of measles vaccine for prevention of acute lower respiratory infections in children. BMC Public Health 2011 11(Suppl 3):S31. 